\title{
ARTA EXCESULUI ȘI A COMPROMISULUI
}

\author{
Adriana BOANTĂ
}

DOI 10.46522/CT.2021.01.04

\author{
Abstract \\ Art of excess and compromise
}

An investigation of the codependent relationship between the work-author-commanditaire and its implications circumscribed to the "new order", imposed by the grid of values established by the political-cultural context during the communist totalitarian regime.

\section{Keywords:}

ideology, propaganda, visual art, homage art, kitsch

[...] atunci când oamenii întorc spatele minciunii, minciuna incetează pur şi simplu să mai existe. Aidoma unei maladii contagioase, ea nu poate exista decât cu concursul oamenilor. (Aleksandr Soljeniţîn, Nu trăiți în minciună, 1974)

\footnotetext{
semenea tuturor regimurilor totalitare, și cel comunist a inițiat, odată cu preluarea puterii, o politică a excesului, susținută de o campanie agresivă de impunere a propriei ideologii, instituind măsuri draconice de control. Aplicate sistematic atât persoanelor fizice (intelectualităţii, în mod special), cât și instituțiilor, acestea vizau „dezagregarea

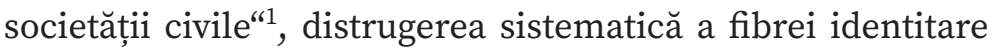

1. Jean-François Soulet, Istoria comparată a statelor comuniste din 1945 până în zilele noastre, trad. Silvia Albişteanu și Ana Zbarcea, colecția „Historia“, Editura Polirom, Iași, 1993, p. 43.
} 
și crearea unei noi „mitologii“ sau, mai bine spus, a unei „contra-mitologii“. Desacralizarea este, așa cum, de altfel, remarca Mircea Eliade, semnul unei societăți aflate în derivă: „Străbatem o criză a sacrului, o dezintegrare a unei bogate structuri simbolice, odinioară instituționalizată și astăzi efectiv consumată. Acordul perfect între subiect și obiect, care se reflectau unul într-altul, nu mai există““2.

Potrivit politologului american Murray Edelman, atunci când în ecuația puterii intră factorul ideologic, miturile nu se dezvoltă doar ca simple ficțiuni, ci devin credințe acceptate pe scară largă $\breve{3}^{3}$. Mitologia puterii utilizează un instrumentar persuasiv care mizează, aproape invariabil, pe factorul emoțional, eludând aproape în totalitate aspectele raționale.

Academicianul Mircea Malița identifică ,șapte păcate capitale“ care contribuie la statuarea acestei ,contra-mitologii“"ce domină spațiul totalitarist românesc: „detronarea rațiunii“, „denigrarea civilizațiiei“, „dispariția universalității“ și proliferarea „particularismului comunitar“, „obnubilarea comunicării“, „adevăr consensual“, și „multiplicitatea ireconciliabilă de practici discursive și sociale“ ${ }^{\text {, }}$, cărora le-am putea adăuga reformularea canoanelor estetice, prin alterarea modelului de reprezentare.

Desigur, comunismul nu s-ar fi putut afirma, impune și menține în absența unui sistem coercitiv și punitiv, care a dat naștere unui așa-zis „terorism de stat“, în expresia lui Ernesto Garzón Valdés, fenomen care se manifestă pe trei direcții: impunerea ideologiei partidului unic; înființarea unui organ propagandistic performant care să legitimeze și susțină necondiționat mesajul politic; înlăturarea non-afiliaților

2. Apud Pierre Brunel, Frédéric Mancier, Matthieu Letourneux (coord.), Miturile secolului XX, vol. 2, traducere de Sanda Oprescu, București, Editura Univers, 2003, p. 398

3. Murray Edelman, Politica și utilizarea simbolurilor, traducerea de Ruxandra Nichita, colecția „Opus“, Iași, Editura Polirom, 1999, p. 101. 4. Mircea Maliţa, Zece mii de culturi, o singură civilizație - spre geomodernitatea secolului XXI, prefața Ricardo Díez-Hochleitner, București, Editura Nemira, 1998, p. 101-107. 
partinici și combaterea oricărei forme de insubordonare. „Terorismul de stat“ a fost întreținut prin activarea unui aparat represiv, bazat pe o fermă ,disciplină interioară“, creat pentru consolidarea regimului, dar mai ales pentru intimidarea oricărei forme de disidența venită din partea oponenților şi a societății, în general.

La rândul său, în consemnările diaristice cuprinse în Jurnalul unui jurnalist fără jurnal, scriitorul Ion D. Sîrbu descrie cu luciditate și acribie mecanismul prin care acționează regimul comunist, al cărui sistem triadic format din frică, foame și forță a sufocat societatea și smintit conștiințele. Acționând ca o veritabilă „triadă a răului“, comunismul a răsturnat sisteme de valori și credințe care păreau imuabile - „ne mutăm de pe ancestrala frică de Dumnezeu pe frica de vecin, prieten, milițian. De pe foamea de adevăr, pe foamea de mâncare, de pe speranța de mâine, pe speranța de pâine ${ }^{\text {“5 }}$.

Megalomania, egocentrismul, setea de putere, fanatismul ideologic sunt patru trăsături definitorii ale excesului care se încuibase adânc în toate structurile sociale ${ }^{6}$. În acest context, cultivarea imaginii de sine, și tot ce a însemnat mecanismul propagandistic care a dat naștere cultului personalității, asociat imaginii prezidențiale, apare ca o strategie compensatorie pentru a camufla actele de abuz. "Mitul salvatorului“ - surprins de Raoul Girardet în lucrarea Mituri și mitologii politice - apare frecvent în discursul politic al propagandei. Definitorie pentru societățile totalitare, noua mitologie modifică radical raportul dintre putere și imaginarul politic.

Imaginea puterii devine un construct care are la bază o ideologie controlată și impusă de propagandă, prin intermediul artei, prin care se încerca crearea unei noi iconografii, ca strategie compensatorie menită să camufleze lipsa de consistență și de legitimitate a unui sistem abuziv. Prin

5. Ion D. Sîrbu, Jurnalul unui jurnalist fără jurnal, vol.2, Exerciţii de luciditate, Editura Scrisul Românesc, 1993, p. 310.

6. Referindu-se la torționarul său Eugen Țurcanu, scriitorul Paul Goma face în Patimile după Piteşti, un portret cutremurător al „reeducatorului“, „olarul“ său din „Iadul“ de la Pitești, un personaj demonic marcat de nebunie şi grandomanie. 
pârghiile politice pe care le folosește ca instrumente de control și persuasiune de care dispunea, Propaganda a reușit să edifice o (supra)realitate, o lume distopică, prin care istoria este suprimată și realul este confiscat, fiind înlocuit cu o suprarealitate. O „irealitate“, zugrăvită în chip ideal, în care imaginea devine „un instrument de condiționare, de oprimare, într-un cuvânt, un înlocuitor al violenței“"

Edelman pune în evidență dinamica grupurilor în societățile opresive, remarcând inversarea raportului de dominare între grupul majoritar și cel minoritar. Astfel, grupul mic (Partidul), prin pârghiile de putere pe care le deține, își însușește în mod abuziv bunurile comune pentru a le aservi intereselor partinice, în timp ce grupul majoritar (societatea) este privat de drepturile legitime, fiind pus în imposibilitatea de a-și apăra drepturile.

Falia creată ca urmare a mișcărilor tectonice politice a împărțit societatea românească între un „Noi“ aservit in corpore Partidului, căruia i s-a interpus un iluzoric „Ei“, de gherilă, format din cei care au refuzat înregimentarea. În acest context, trebuie subliniat rolul jucat de „rezistența“ culturală și artistică formată din scriitori, regizori, artiști vizuali, sculptori, arhitecți etc. Într-o mare de adaptabili, de „,ăldicei“" ${ }^{\text {, }}$, damnații au așteptat bovaric „liberalizarea“ ideologică și „dezghețul“ dejist, asumându-și da capo rolul de ,element pierdut“9 sau, în cel mai bun caz, statutul de exilat. Ei nu au legitimat regimul opresiv, refuzând procesul de reeducare sau asimilarea prin „,colectivizarea" artistică. Strigătul lor a reprezentat furia omului care refuză „ubuizarea“ sau „rinocerizarea“. „Violența nu-și așază laba grea nici în fiecare zi, și nici pe fiecare umăr; ea nu cere de la noi decât supunerea noastră la minciună (...) cheia eliberării

7. Jean-Jacques Wunenburger, Imaginariile politicului, trad. lonel Bușe și Laurențiu Ciontescu-Samfireag, Bucureşti, Editura Paideia, 2005, pp. 61-62.

8. Apud Dostoievski, Idiotul, cap. La Tihon (Spovedadia lui Stavroghin), trad. Nicolae Gane, Iași, Editura Polirom, 2011, p. 905.

9. Apud Mihai Pelin, Deceniul prăbușirilor (1940-1950). Viețile pictorilor, sculptorilor și arhitecților români între legionari și comuniști, seria „Clar Obscur“, București, Editura Compania, 2005, p. 413. 
noastre: refuzul de a participa personal la minciună! Puțin importă dacă minciuna acoperă totul, dacă ea devine stăpână peste tot, să fim refractari cel puțin asupra acestui punct: să nu devină prin mine. Căci atunci când oamenii întorc spatele minciunii, minciuna încetează pur și simplu să mai existe. Aidoma unei maladii contagioase, ea nu poate exista decât cu concursul oamenilor"10.

În planul creației, mesajul ideologic a condus la parazitare artei și la deconstruirea grilei esteticii, prin impunerea modelului unic: realismul socialist (concept impus tuturor țărilor din fostul bloc comunist): „Realismul socialist se vrea o oglindă a unei realități inexistente... De vreme ce trebuie afirmată irealitatea drept singura realitate, trebuie menținute toate trucurile iluzionismului fotografic. Tablourile sunt confecționate în maniera panoramelor din secolul al XlX-lea, pentru ai da spectatorului impresia că se află acolo... Arta devine irealistă pe măsura «realismului» său și farmecul său se reduce la tehnica sumară a celui care așază decoruri la Hollywood... Atât de perfect se simbolizau unul pe celălalt realismul socialist și Partidul - estetica acționând prin mijloacele politicii și Partidul acționând în mod estetic -, încât ele nu au putut niciodată să se despartă“11.

Începând cu anii ‘70, după ,Tezele“ din iulie, strategia cultural-politică a fost dominată de noile realități ideatice reprezentate de umanismul socialist, impus ca direcție oficială de reprezentare în artă, al cărui caracter ilustrativ-didacticist urmărea educarea masele în spiritul valorilor socialiste. „Literatura noastră, literatura societății socialiste, participă direct la vasta ofensivă ideologică pentru formarea conștiinței noi, socialiste, și lichidarea influențelor educației și moralei burgheze ${ }^{* 12}$.

Noul realism socialist glorifica trecutul istoric al poporului român sau „fabrica“ istoria ipostaziindu-l pe „Conducătorul suprem" ca pe un om providențial, aidoma marilor

10. Apud Alain Besançon, Originile intelectuale ale leninismului, trad. Lucreția Văcar, colecție: „Seria Alain Besançon“, Bucureşti, Editura Humanitas, 2007, p. 358.

11. Ibidem, p. 354.

12. Secolul 20, ianuarie, 1961. 
personalități ale istoriei, cu descendență nobilă. Tocmai de aceea una dintre direcțiile privilegiate în artă a fost cea de tip monumental: pictura murală și sculptura monumentală. Prin conținutul tematic, soluțiile tehnice și rezolvările plastice, aceasta completează și subliniază în aceeași manieră stilul excesiv, specific „esteticii“ realismului socialist.

Mulți artiști își asumă ghidajul ideologic, ,programul estetic“ oficial, stimulați de sume consistente primite din partea autorităților, prin așa-zisele „ajutoarele de creație“ și de numărul mare de comenzi venite din partea „Comitetului pentru artă“ din cadrul Ministerului Culturii. Pentru a o analiză a modului în care imaginarul politic devine obiect și subiect al adulației publice, trebuie să ne îndreptăm analiza către sursa principală de diseminare a mesajului ideologic, și anume artele vizuale care reflectă poate cel mai clar iconografia puterii. „Faptul că de atâția ani, aproape șase, nu am folosit cinematograful arată cât de needucați suntem, ca să nu o spunem direct, proști. Arma asta, care urlă să fie folosită, e cel mai bun instrument al propagandei politice sau orice formă a propagandei doriți, o propagandă accesibilă oricui, care rămâne în minte... ${ }^{\text {13 }}$, remarca Lev Troțki în controversatul articol „Vodka, Biserica și Cinematograful“" apărut în iulie 1923, în publicația Pravda.

Un număr impresionant de cărți, publicații, programe și comitete, precum Cultura poporului, Îndrumătorul cultural Programe de brigăzi artistice de agitație, Indreptarul Instructorului Brigăzii Artistice de Agitație, Comitetul de Stat pentru Cultură și Artă, Comitetul de Stat pentru Cultură și Artă, se ocupau cu educația socialistă a maselor, reflectând activitatea cultural-educativă a partidului, dar și urmărind să ,îndeplinească misiunea de onoare de a fi cronicarii acestui timp de grandioase și cutezătoare înfăptuiri“, peste care veghea, imperturbabil „efigia prestigioasei personalități, cel dintâi și cel mai iubit fiu al țării (Nicolae Ceaușescu s.m.).“14 „Alegându-1 să-i conducă destinele,

13. Richard Taylor, Film Propaganda: Soviet Russia and Nazi Germany, Londra, I.B. Tauris, 2009, p.35.

14. Fragmente din Scrisoare adresată tovarășului Nicolae Ceaușescu de către Consiliul de Conducere al UAP și Comisia de Cenzori, 1978, publicată în revista Arta, nr. XXV/1978, pp. 8-9. 
poporul a ales pe cel mai bun fiul al său, călăuză energică și inspirată, luminată de ceea ce e mai înălțător în trecutul național [...]. Nicolae Ceaușescu reprezintă ceea ce e mai bun în noi, iar această aniversare (n.r. - dictatorul împlinea frumoasa vârstă de șaizeci de ani) este o mare sărbătoare a întregului popor (Sabin Bălașa, Teatrul, nr. 1, XXIII, ianuarie 1978).

Desigur, principalele publicații din România, Scânteia, Arta plastică și Secolul 20 - „o revistă de literatură mondială contemporană, a cărei trebuință și însemnătate e de la sine înțeleasă, într-o cultură națională înfloritoare, dornică de a primi și răsfrânge imaginea prezentului în lume ${ }^{* 15}$ - vor dedica spații largi declarațiilor lui Nicolae Ceaușescu susținute în cadrul Congresului al IX-lea al Partidului Comunist Român, privind diversificarea și „liberalizarea“ formelor de exprimare, câștigarea unei aparente ,autonomii“, prin limitarea parțială a libertății artistului în alegerea subiectelor abordate, câtă vreme acestea reflectă prezentul glorios: „,...] Artei și literaturii le sunt proprii preocuparea pentru înnoire și perfecționarea creatoare a mijloacelor de exprimare artistică, diversitatea de stiluri [...] este necesar să se creeze în diferite stiluri. Putem spune creatorilor de artă: alegeți tot ceea ce credeți că este mai frumos în culoare, mai expresiv în grai. Redați realitatea cât mai variat.“16

Potrivit programului editorial, publicat în primul număr al revistei Secolul 20, textele din literatura străină (poezie, proză scurtă, traduceri, fragmente de roman, piese de teatru ș.a.m.d.) publicate în revistă vor fi analizate potrivit grilei de interpretare și selecție oficială, în „spiritul marxism-leninismului, supunând unei critici științifice, combative, ideologia burgheză, sub toate formele ei“.

Revista Secolul 20, la fel ca multe alte publicații, a încercat să supraviețuiască cenzurii prin adoptarea în paginilor ei a textelor care, într-un limbaj de lemn, glorifica regimul

15. Secolul 20, ianuarie 1961.

16. Fragment din Raportul Comitetului Central prezentat de Nicolae Ceaușescu la Congresului al IX-lea al Partidului Comunist Român, publicat în revista de literatură universală (editată de Uniunea Scriitorilor din RPR) Secolul 20, anul V, nr. 7-8, iunie-iulie, pp. 4-5. 
comunist și pe secretarul general al partidului, Nicolae Ceaușescu. În editorialul Perspective, apărut în revista Secolul 20 la aniversarea a cinci ani de la apariția primului număr al publicației, redactorul-șef Marcel Breslașu scria: „Secolul 20 se va strădui și pe viitor să țină pasul vieții și al vremii“ și deschide paginile revistei cu „prețioasele îndrumări date artiștilor și literaților de către secretarul general al Partidului, tovarășul Nicolae Ceaușescu“17. Desigur, compromisul (calculat) făcut de redacție a avut o miză mult mai importantă: publicarea în paginile revistei a adevăratei literaturi și a artiștilor plastici importanți ai vremii: „Cred că n-a existat scriitor important pe plan mondial, care să fi adus ceva nou și vrednic de atenție în literatura lumii de care Secolul 20 să nu se fi ocupat, pe care Secolul 20 să nu ni-l fi prezentat măcar sumar" - precizează Zaharia Stancu, președintele Uniunii Scriitorilor, cel care a contribuit substanțial la nașterea revistei Secolul 20. Primul număr, apărut în 1961, a fost editat de Uniunea Scriitorilor, fiind o revistă de literatură universală, din a cărei redacție făceau parte Maria Banuș, Mihai Beniuc, Savin Bratu, Marcel Breslașu, Paul Georgescu, Mihnea Gheorghiu, Eugen Jebeleanu, Mihai Novicov, Zaharia Stancu și Tudor Vianu, iar începând cu numărul 1981 ea devine o revistă de literatură universală, arte, dialog al culturilor.

Aceeași politică a compromisului, transformată în strategie de supraviețuire va fi adoptată și de revista Arta. Prezența în paginile revistei a câtorva articole rezervate propagandei și promovării politicii oficiale, alături de reproduceri după lucrări ale artiștilor oficiali, a asigurat supraviețuirea publicației în condițiile grele impuse de regimul opresiv. Apărută în 1954, Arta a rămas, până la căderea regimului comunist, singura revistă din România dedicată aproape exclusiv reflectării critice a fenomenului artelor plastice contemporane.

Cele mai importante voci ale criticii de artă din România au contribuit timp de șase decenii la conținutul editorial al revistei: Dan Grigorescu, Vasile Drăguț, Ion Frunzetti, Amelia Pavel, Răzvan Theodorescu, Mihai Drișcu, Anca Arghir, Olga Bușneag, Virgil Mocanu, Marius Tătaru, Ioana Vlasiu, Alexandra Titu,

17. Secolul 20. nr. 7-8/ 1965, p. 9. 
Radu Procopovici, Andrei Pintilie, Gheorghe Vida etc. - transformând revista Arta în principala platformă de promovare pentru toate generațiile de artiști: consacrați și debutanți, deopotrivă.

\section{Arta excesului}

Controlată ideologic, lumea artei, dominată de favoritisme, frică și frivolitate, o combinație între iluzionism și oportunism veleitar, pune în scenă un spectacol kitsch cu scenotehnică și figurație impresionantă care colează ca într-un imens tablou constructivist: uzine mamut, schele precum arcele butante, câmpuri mănoase, poporul muncitor entuziast.

Politizarea discursului estetic a generat o acumulare impresionantă de produse artistice și pseudo-artistice (kitsch), care a dat naștere unei iconografii oficiale de proporții pantagruelice. În arta omagială, retorica propagandistică devine mai importantă decât stilistica și discursul estetic, iar cele mai evidente manifestări ale acesteia se regăsesc în portretistica, arta statuară și artele decorative din perioada (supra) realismului socialist. Acesta includea în primul rând portretele ctitorilor „Epocii de aur“, Nicolae și Elena Ceaușescu, dar și ilustrări ale momentelor-cheie din trecutul și prezentul glorios al Partidului Comunist Român.

„Noua realitate“ se reifică din rândurile de istorie, selectate după criteriile subiective, care, odată alăturate, deformează, falsifică, confiscă istoria, prin decupajul sau surplusul adăugat informației prime. Amplificarea unor evenimente sau inventarea lor, cultivarea detaliului minor, care căpăta dimensiuni hiperbolice, și a construcțiilor alegorice, au alimentat nenumăratele „fantasme ale imaginației colective“ ${ }^{18}$, remarca Véronique Richard.

Producția de obiecte artistice urmează direcțiile marxiste potrivit cărora se „creează nu numai un obiect pentru subiect, ci și un subiect pentru obiect. „[...] Ea (producția, s.m) produce, deci, obiectul de consum, modul de consum și nevoia de consum ${ }^{“ 19}$.

18. Pierre Brunel (coord.), Frédéric Mancier, Matthieu Letourneux, Miturile secolului XX, vol.2, trad. Sanda Oprescu, Editura Univers, București, 2003, p. 103.

19. Cf. Abraham Moles, Psihologia kitsch-ului (Arta fericirii), trad. 
Astfel, în 1978, Muzeul de Istorie al R.S. ${ }^{20}$ rezervă un amplu spațiu expozițional lucrărilor asociate cultului personalității lui Nicolae Ceaușescu. Zece ani mai târziu, în 1989, fondul de obiecte omagiale aflat în patrimonial muzeal depășea zece mii de exponate.

Expresie a lipsei măsurii, „noua artă“, dominată de patetism edulcorat și un optimism exacerbat, propune o realitatea idealizată, dar falsă ca o dioramă. Formulele vizuale adoptate erau strict controlate, pentru a corespunde "noului canon“ estetic şi, implicit, intereselor Partidului. De altfel, toate lucrările care făceau trimitere la simbolurile comunismului, la cuplul prezindențial, precum și la „protipendada“ Partidului trebuiau supervizate de Secția de Propagandă și Presă și de Comitetul Național pentru Artă. Sabin Bălașa, prim-expozabilul agreat de Propagandă, și, cu el, și alții, mărturisea cu cinism, lipsit de remușcări și decență, trezit parcă dintr-o visare narcotizantă, sau poate doar se ,îmbărbăta pentru a-și birui frica“21, că „dintotdeauna artiștii mari au executat comenzi, numai amatorii fac doar ce le place [...] De ce să mă vait? Să spun că am fost dizident? M-am ferit de dizidență, de văitături, că dizidența e un fel de văitătură [...] în loc de artă, stăpânii care la noi au făcut realismul socialist, la voi au făcut postmodernismul sau cum îi ziceți voi. [...] Eu comunismul l-am construit cu nuduri [...] Sunt împăcat cu întreg universul [...] Nu-i combat pe alții, eu mă afirm pe mine.“22

Prin preocuparea obstinentă către un hiper-decorativism flamboaiant, arta „omagiilor“ ia forme grotești, transformând-se în artă kitsch. Dar mai mult decât să surprindă o estetică vizuală, arta omagială redă o stare de spirit care se materializase în obiecte. Proiecție a unui sentimentalism desuet, artificial și vulgar, dar adeseori amuzant prin excesul etalat, arta omagială exprimă acea caracteristică definitorie

Marina Rădulescu, Editura Meridiane, Colecţia „Curente şi sinteze“, Bucureşti, 1980, p. 19

20. Muzeul de Istorie al R.S.R sau „Muzeul nostru“ după apelativul folosit de Nicolae Ceaușescu.

21. Octavian Paler, Don Quijote în Est, Editura Polirom, Iași, 2010, p. 227 22. Sabin Balașa: Am avut și simțul creației și al procreației (https://revistatango.ro/sabin-balasa-am-avut-si-simtul-creatiei-si-al-procreatiei-130, accesat la 28.02.2021). 
kitsch-ului surprinsă de Abraham Moles: „faptul că un obiect este mai mare sau mai mic nu are, în sine, nimic kitsch. Este kitsch numai ideea unei redări disproporționate a dimensiunilor față de cele reale ale obiectului“'23.

Asemenea propagandei, al cărei demers al convingerii/ constrângerii urmărește manipularea publicului, convertirea lui, prin folosirea unor formule de seducție (pervertire), kitsch-ul mizează pe mecanisme ale artei în construirea discursului vizual. „Există un kitsch al artei, care se referă fie la obiecte de artă, în sensul clasic al termenului, fie la un anumit tip de aranjare a acestora într-un cadru dat şi la relațiile dintre ele“24. De altfel, kitsch-ul reprezintă expresia crizei profunde a valorilor culturale și a deturnării artei de la mesajul său înalt, chiar dacă „o fărâmă de kitsch există în orice formă de manifestare a artei“, după cum susține Hermann Broch.

Criticul de artă Gillo Dorfles asociază fenomenul kitsch tuturor manifestărilor artistice supuse unui proces de serializare, specific producției de masă, care răspund nevoii imediate a publicului larg, pentru un divertisment facil, fără să implice un efort de analiză. Hermann Broch susține că sistemul kitsch impune ,adepților săi «Să lucreze frumos!», pe când sistemul artei presupune îndemnul moral «Să lucrezi bine!». Kitsch-ul este răul din sistemul de valori al artei“ ${ }^{“ 25}$.

Inspirat de studiul-eseu Răul din sistemul de valori al artei (1933) semnat de Hermann Broch, în care enunță principalele diferențe dintre artă și kitsch ${ }^{26}$, criticul de artă

23. Abraham Moles, op. cit. p. 19.

24. Ibidem, p. 19

25. Apud Matei Călinescu, Cinci feţe ale modernităţii. Modernism, avangardă, decadenţă, kitsch, postmodernism, ediţia a doua, revăzută şi adăugită, traducere din limba engleză de Tatiana Pătrulescu şi Radu Ţurcanu, traducerea textelor din „Addenda“ de Mona Antohi, postfaţă de Mircea Martin, Iaşi, Editura Polirom, 2005 p. 251.

26. În acest eseu, Broch identifică kitsch-ul ca fiind „răul din cadrul sistemului de valori al artei“. Broch susține că kitsch-ul depinde de parazitarea artei prin adoptarea strategiilor ei de comunicare, limitându-se la imitarea convențiilor, în încercarea permanentă de a obține „frumusețe“ în locul „adevărului“. 
american Clement Greenberg susține în Avangarda și kitsch-ul (1939) apărut în numărul 5 al revistei americane The Partisan Review ${ }^{27}$, că kitsch ${ }^{28}$-ul împrumută din arsenalul de mijloace de expresie și comunicare ale artei „mijloacele, instrumentele, trucurile, strategiile, metodele, temele ${ }^{\text {“29 }}$ pe care le oferă mare publicului într-o formă alterată, recontextualizate, și astfel le conferă un alt sens și o altă importanță. Acestor puncte de vedere li se alătură și cele ale lui Ludwig Giesz (Fenomenologia kitsch-ului), Viktor Engelhardt, Gillo Dorfles (Kitsch: Lumea prostului gust), Umberto Eco (Structura prostului gust) sau Tomáš Kulka (Kitsch și artă) ${ }^{30}$

Definindu-se ca opoziție ireductibilă față de valorile autentice ale artei, kitsch-ul marchează, sub raport structural-estetic, un exces, așadar, o lipsă de măsură în raport cu modelul artistic pe care îl parazitează și calchiază. Principiul de reprezentare a kitsch-ului se bazează pe imitație, dar și pe reproducerea servilă, până la distrugerea modelului-reper. Kitsch-ul este prin definiție alterare, inadecvare, exces. Un exces de mijloace în raport cu nevoia de reprezentare și semnificare. Lipsa lui de măsură este expresia abundenței, aglutinării (ornamentică, simboluri, proporții etc.) și a excesului cumulativ, dar și a proliferării lui excesive. ,Legat indisolubil de artă“"31, deconstruind strategii vizuale și rețete narative clișeistice, fenomenul kitsch este asociat cu subproducțiile artistice, cu tot ceea ce este fals și neesențial, strident și ostentativ, în același timp, supraîncărcat și grandios, vulgar și patetic, frivol și superficial. Rezultatul este absența originalității, negarea autenticității, prevalența mimetismului servil, degenerarea în clișee,

27. Partisan Review, Vol. 6, Nr. 5, Toamna: 1939, p. 40. (http://www. bu.edu/partisanreview/books/PR1939V6N5/HTML/files/assets/basic-html/index.html\#I (accesat la 24 febr.2021).

28. Stabilirea sensului etimologic al termenului kitsch face trimitere la verbul „verkitschen“, care însemnă ,a degrada, a schimba, a strica“. 29. Clement Greenberg, Avant-Garde and Kitsch, adresa online: http:// xroads.virginia.edu/ DRBR2/greenburg.pdf (accesat 27.02.2021) 30. Tomáš Kulka, Kitsch and Art, Pennsylvania State University Press, University Park, 1996, p. 14.

31. Cf. Hermann Broch. 
standardizarea, serializarea, inflația (excesul). Rezumând caracteristicile enunțate mai sus și apelând la clasificările făcute de Abraham Moles, distingem patru dintre cele cinci principii ale kitsch-ului enunțate de acesta pe care le putem asocia artei excesului din perioada comunistă: ,principiul mediocrității“, „principiul sinesteziei“, „principiul acumulării“ și ,principiul inadecvării“‘32.

Mediocritatea, caracteristica „tragică“ a kitsch-ului, așa cum o numește Moles, rezidă din lipsa de măsură (hybris), multitudinea aglutinărilor, disproporția în folosirea și distribuirea elementelor și excesul de mesaje transmise concomitent de un obiect sau de o aglomerare de obiecte. Dar tocmai mediocritatea le conferă produselor kitsch ,s,ansa la tragic“, le desăvârșesc menirea, deoarece acestea ,dobândesc un autentic caracter de fals și obțin un surâs condescendent din partea consumatorului, care se crede superior lor, din moment ce le judecă ${ }^{\text {“33. }}$

Pornind de la principiul anterior enunțat, se desprind „principiul sinesteziei“ și cel al „,acumulării“, care apelează la o multitudine de canale senzoriale pentru a pune în evidență mesajul. Frenezia acumulării excesive de lucruri, stiluri, mijloace, tehnici, conduce la depășirea limitei și la supralicitarea inutilă a formei, dar și a privirii spectatorului.

Suprasolicitarea mijloacelor intervine ca o strategie compensatorie, de umplere a vidului referențial creat, fie prin lipsa de consistență, fie prin lipsa de sens sau de adecvare între conținut și formă.

De altfel, ,principiul inadecvării“, enunțat prima dată de Viktor Engelhardt în lucrarea Kitsch-ul (Der Kitsch), readus în discuție de Moles, surprinde esența kitsch-ului, pune în evidență a) contradicția și dintre obiectul și subiectul reflectat; b) neconcordanța dintre forma și esență; c) neadecvarea formei la subiect. Este kitsch supradimensionarea cultului lui Ceaușescu, a „operei omagiilor" și a tuturor formelor artistice care îl prezintă într-un mod idealizat, exagerându-i atributele. Sunt kitsch triumfalismul, festivismul, zgomotul, poleiala și manierismul întâlnit în reprezentare imaginii sale.

32. Abraham Moles, op. cit., p. 60.

33. Ibidem, p. 65. 


\section{Concluzie}

Imaginile triumfalismului propagandistic și dramatismul emoțional asociat figurii conducătorului suprem domină imaginarul politic în regimul comunist. Imaginarul politic reflectat de multitudinea de picturi, statui, tapiserii, monede surprinde printr-o continuitatea stilistică, care se află în strânsă legătură cu modelul canonic impus. Toate reprezentările cuplului prezidențial, fie că este vorba de tablouri fresce, statui, plachete, monede omagiale, pancarte, denotă o impunere a unei direcții estetice, menite să compenseze prin imaginea idealizată lipsa unei descendențe și biografii pe măsura realității și viziunii mitologizate surprinse de acestea.

\section{Bibliografie:}

\section{Volume:}

BESANÇON, Alain, Originile intelectuale ale leninismului, traducere de Lucreția Văcar colecție: „Seria Alain Besançon“, Bucureşti, Editura Humanitas, 2007.

Brunel, Pierre (coord.), Letourneux, Matthieu, MANCier, Frédéric, Miturile secolului XX, vol.2, traducere de Sanda Oprescu, București, Editura Univers, 2003.

CĂLINESCU, Matei, Cincifețe ale modernităţii. Modernism, avangardă, decadenţă, kitsch, postmodernism, ediţia a II-a, revăzută şi adăugită, traducere din limba engleză de Tatiana Pătrulescu şi Radu Ţurcanu, traducerea textelor din „Addenda“ de Mona Antohi, postfaţă de Mircea Martin, Iaşi, Editura Polirom, 2005.

CEAHOTIN, Serghei, Violul mulţimilor prin propaganda politică, studiu de Mihnea Columbeanu, Editura Antet, Filipeştii de Târg, 2002.

CIOROIANU, Adrian, Comuniştii înainte de comunism, procese şi condamnări ale ilegaliştilor din România, București, Editura Universităţii din Bucureşti, 2014.

Comisıa Prezidenţială pentru Analiza Dictaturii Comuniste din România - Raport Final, București, Editura Humanitas, 2007.

Compagnon, Antoine, Demonul teoriei. Literatură şi bun simț, traducere de Gabriela Marian şi Andrei-Paul Corescu, Cluj-Napoca, Editura Echinox, 2007. 
MICU, Daniela, MILITARU, Petrişor (coord.), Condiţia scriitorului) intelectualului disident în România comunistă, Craiova, Editura Aius Printed, 2012.

EDElman, Murray, Politica și utilizarea simbolurilor, traducerea de Ruxandra Nichita, colecția „Opus“, Editura Polirom, Iași, 1999.

FOUCAUlT, Michel, A supraveghea și a pedepsi: nașterea închisorii, traducere din limba franceză, postfață și note de Bogdan Ghiu, ediția a II-a, Pitești, 2005.

GogeA, Vasile, Voci în vacarm. Un dialog cu Editura Paralela 45, Monica Lovinescu și Virgil Ierunca, postfaţă de Liviu Antonesei, Editura Eikon, Cluj-Napoca, 2010.

IERUNCA, Virgil, Dimpotrivă, București, Editura Humanitas, 1994.

IONESCO, Eugène, Teatru, vol. II, trad. Rodica Șelmaru, Editura pentru literatură universală, București, 1968.

Kemenov, Vladimir Simionovici, Caracteristicile a două culturi, București, Editura Partidului Comunist Român, 1948.

KoŁAKOWSKI, Leszek, Principalele curente ale marxismului. III. Prăbușirea, traducere de S.G. Drăgan, București, Curtea Veche Publishing, 2009.

KulkA, Tomáš, Kitsch and Art, University Park, Pennsylvania State University Press, 1996.

MALIŢA, Mircea, Zece mii de culturi, o singură civilizație - spre geomodernitatea secolului XXI, prefața Ricardo Díez-Hochleitner, București, Editura Nemira, 1998.

MARX, Karl, ENGELS, Friedrich, Ideologia germană, București, Editura de Stat pentru Literatură Politică, 1956.

MERIŞANU, Nicolae; TAloş, Dan, Antologia ruşinii după Virgil Ierunca, București, Editura Humanitas, 2009.

Mitchievici, Angelo; STANOMIR Ioan, Comunism inc.: Istorii despre o lume care a fost, București, Editura Humanitas, 2016.

Moles, Abraham, Psihologia kitsch-ului. Arta fericirii, traducere de Marina Rădulescu, colecţia „Curente şi sinteze“, București, Editura Meridiane, 1980.

MUŞAT, Carmen, „Teoria literaturii - între proletcultism şi realism socialist", în Explorări în trecutul şi în prezentul teoriei literare româneşti (coord. Mircea Martin), Bucureşti, Grupul Editorial Art, 2006.

PALER, Octavian, Don Quijote in Est, Iași, Editura Polirom, 2010.

PĂIUŞan, Cristina; Ion, Narcis Dorin; RETEgan, Mihai, Regimul comunist din România. O cronologie politică (1945-1989), București, Editura Tritonic, seria „Istorie“, 2002. 
PELIN, Mihai, Deceniul prăbușirilor (1940-1950). Viețile pictorilor, sculptorilor și arhitecților români între legionari și comuniști, seria „ClarObscur“, București, Editura Compania, 2005.

SOULET, Jean-François, Istoria comparată a statelor comuniste din 1945 până în zilele noastre, traducere de Silvia Albişteanu și Ana Zbarcea, colecția „Historia“, Iași, Editura Polirom, 1993.

TAYLOR, Richard, Film Propaganda: Soviet Russia and Nazi Germany, seria „Cinema and Society“, London, I.B. Tauris, 2009.

WUNENBURGER, Jean-Jacques, Imaginariile politicului, traducere de lonel Bușe și Laurențiu Ciontescu-Samfireag, Bucureşti, Editura Paideia, 2005.

\section{Reviste:}

Arta plastică, nr. 4/1966.

Arta plastică, nr. 5/1966.

Contemporanul, nr. 18 (500), 4 mai 1956.

Partisan Review, nr. 5, vol. 6, 1939.

Scânteia, nr. 2464 din 27 septembrie 1952.

Scânteia, 25 iunie 1959.

Secolul 20, nr. 7-8/1965.

Secolul 20, nr. 2/1961.

\section{Resurse web:}

https://hi-storylessons.eu/ro/culture/proletcultism-si-realism-socialist-1948-1965/;

https://beta.dela0.ro/antologia-rusinii-ceausescu-ce-e-mai-bun-innoi/;

http://arhiva.rador.ro/info4.shtml?cat=1281\&news=338665;

http://old.presidency.ro/static/rapoarte/Raport_final_CPADCR.pdf;

http://www.bu.edu/partisanreview/books/PR1939V6N5/HTML/

files/assets/basic-html/index.html\#I;

http://www.hetel.ro/nicolae-ceausescu-in-tablouri/;

https://www.modernism.ro/2019/01/21/ceausescu-in-pictura/;

https://revistapolis.ro/329-editorial-nostalgia-mioara-anton/. 